\title{
STUDI CEMARAN MIKROBA PADA PRODUK PANGAN TRADISIONAL "LAWAR PUTIH DAGING BABI” DI KECAMATAN DENPASAR UTARA
}

Study of Microbial Contamination in Traditional Food Products "Pork White Lawar" in North Denpasar Subdistrict

\author{
Ni Ketut Sri Agustini ${ }^{1)}$, I Nengah Kencana Putra ${ }^{2)}$, Dewa Gde Mayun Permana ${ }^{2)}$ \\ ${ }^{1)}$ Mahasiswa Program Studi Ilmu dan Teknologi Pangan, Fakultas Teknologi Pertanian, Universitas Udayana \\ ${ }^{2)}$ Dosen Program Studi Ilmu dan Teknologi Pangan, Fakultas Teknologi Pertanian, Universitas Udayana \\ Kampus Bukit Jimbaran, Badung-Bali
}

\begin{abstract}
The aim of this study was to know microbial contamination of white lawar pork and hygiene sanitation practices in some restaurants that sell white lawar pork in North Denpasar subdistrict. The study used a survey method with simple random sampling technique. Sampling was carried out in several restaurants in the North Denpasar subdistrict. The result from this research was served in table, and the data was analyzed by descriptive method. The variables observed were total microbes, E.coli, and Staphylococcus aureus. The results showed that as $45 \%$ of white lawar comply the total microbial requirements of processed meat with heat treatment in Indonesia $\left(<1 \times 10^{6} \mathrm{koloni} / \mathrm{g}\right), 100 \%$ lawar did not comply the requirements of E.coli in processed meat with heat treatment in Indonesia, and 100\% white lawar had comply the requirements of Staphylococcous aureus in processed meat with heat treatment in Indonesia. 100\% of lawar is processed in the morning. The practice of sanitation and hygiene at restaurants in the district of Denpasar Utara is quite good.
\end{abstract}

Keywords: white lawar, microbial contamination, hygiene sanitation

\section{PENDAHULUAN}

Lawar adalah salah satu jenis makanan tradisional Bali yang saat ini makin populer dan makin luas konsumennya. Daging yang biasa digunakan pada pembuatan lawar adalah daging babi. Lawar Bali ada dua jenis, yaitu lawar merah yang mengandung darah segar dan lawar putih yang tidak mengandung darah segar. Lawar putih adalah sejenis lauk pauk yang di buat dari campuran daging babi dengan sayur mayur seperti sayur nangka muda, parutan kelapa, dan buah papaya muda, serta di tambahkan base genep dan tidak menggunakan campuran darah sedikitpun (Suter et al., 2010).

Arihantana (1993) melaporkan dalam penelitiannya E.coli yang ada pada lawar bersumber dari daging mentah, kulit, sayuran yang digunakan, dan juga dari talenan bekas yang dipergunakan. Keracuanan lawar belum pernah terpublikasi sebagai penyebab KLB pada wisatawan, tetapi beberapa studi pernah dilakukan tentang cemaran mikroba pada penyediaan lawar dan semua hanya dilakukan pada lawar merah. Hal ini dibuktikan dari hasil penelitian pada lawar tahun 2013 ditemukan $60 \%$ lawar yang dijual di daerah Sanur terkontaminasi E.coli (Candra et al., 2013) serta penelitian Kinanthini tahun 2014 yang dilakukan di wilayah Ubud ditemukan 83,3\% lawar terkontaminasi E.coli. Kontaminasi tersebut disebabkan karena cara pengolahan, hygiene dan sanitasi pengolah, serta alat yang digunakan pada saat pengolahan lawar (Suter, 2009). Mikroba patogen yang mengkontaminasi daging babi olahan seperti lawar adalah E.coli dan Staphylococcus aureus yang menyebabkan penurunan kualitas serta memiliki dampak yang cukup berbahaya bagi kesehatan. (Supar, 2005).

*Korespondesi Penulis:

E-mail: niketutsriagustini@gmail.com ${ }^{1)}$ 
Berdasarkan uraian diatas, maka diperlukan penelitian yang bertujuan untuk mengetahui cemaran (total mikroba, E.coli, dan Staphylococcus aureus) pada lawar putih daging babi dan praktek sanitasi higiene pada rumah makan di kecamatan Denpasar Utara.

\section{METODE PENELITIAN}

\section{Tempat dan Waktu Penelitian}

Penelitian ini dilaksanakan pada rumah makan yang menjual lawar di kecamatan Denpasar Utara dan Laboratorium Mikrobiologi Pangan Fakultas Teknologi Pertanian, Universitas Udayana. Waktu pelaksanaan pada bulan Agustus sampai September 2018

\section{Bahan dan Alat}

Bahan yang digunakan dalam penelitian ini adalah lawar putih daging babi, larutan PW (Pepton Water), 3M petriflim ${ }^{\mathrm{TM}}$ EC plate ( Ingridients : Polyester flim, polystyrene foam, transfer adhesive, polypropylene film, guar gum, nutrients, hinge tape, lactose, pancreatic digest of gelatin), petriflim ${ }^{\mathrm{TM}}$ AC plate ( Ingridients: Silicone coated paper, polypropylene film, guar gum, Acrylat adhesive- top film, adhsesive - bottom film, hinge tape, media nutrients, sodium pyruvate) dan petriflim ${ }^{\mathrm{TM}}$ STX plate ( Ingredients : Nutrient media coated on paper with foam relatining dam and film cover sheet), aquades, aluminum foil, plastik PE (Polyetilen), dan alkohol $96 \%$.

Alat yang digunakan dalam pengujian ini adalah cold box (Marina cooler), tabung reaksi (Iwaki), pipet volumetric (Iwaki), pipet mikro (Akura), gelas ukur (Pyrex), medical sterilizer (Fortune), enlemeyer $1000 \mathrm{ml}$ (Pyrex), blue tip, gunting, rak tabung, pinset, vortex (Gemmy), bunsen, timbangan analitik (Ohaus), vortex, inkubator (Memert), autoklaf (Hirayama), magnetic stirrer (Thermo scientific), spreader, dan laminar flow.

\section{Rancangan Penelitian}

Penelitian ini dilakukan dengan metode survei dengan teknik pengambilan sampel simple random sampling yaitu teknik untuk mendapatkan sampel yang langsung dilakukan pada unit sampling. Cara tersebut dilakukan bila anggota populasi dianggap homogen dan pengambilan sampel minimal $30 \%$ dari jumlah populasi secara acak dengan cara undian (Sugiyono, 2007). Polulasi rumah makan yang menjual lawar putih adalah 36 rumah makan dan diambil $30 \%$ dari jumlah populasi yakni 11 rumah makan. Data hasil penelitian disajikan dalam bentuk tabel dan dianalisis secara deskriptif.

\section{Variable yang diamati}

Variabel yang diamati pada penelitian ini adalah cemaran mikroba (total mikroba, E.coli, dan Staphylococcus aureus) dianalisi dengan metode tuang pada $3 \mathrm{M}$ petrifilm food safety (Anon., 2017) yang telah dievaluasi oleh AOAC official method dan disesuaikan dengan tentang metode pengujian cemaran mikroba dalam olahan daging (Anon., 2008).

\section{Pelaksanaan Penelitian}

Pengambilan sampel dilakukan pada pukul 09.00 wita di rumah makan yang menjual lawar di kecamatan Denpasar Utara. Alat yang digunakan untuk mengambil sampel berupa wadah plastik dan ice box yang sudah disterilkan dengan alkohol. Adapun cara kerjanya yaitu sampel sebanyak $\pm 100 \mathrm{~g}$ yang dibeli dari masing-masing rumah makan dimasukkan ke dalam plastik lalu disimpan di dalam ice box selama diperjalanan lalu pada pukul 10.00 wita dibawa ke Laboratorium Mikrobiologi Pangan Universitas Udayana untuk dilakukan analisis cemaran mikroba. 


\section{Preparasi Sampel (Anon., 2017)}

Preparasi sampel berdasarkan metode pengujian total mikroba, Coliform dan E.coli, Staphylococcus aureus produk olahan daging dalam SNI 2897:2008. Sampel lawar putih daging babi ditimbang $5 \mathrm{~g}$ lalu dimasukkan ke dalam botol steril yang berisi $45 \mathrm{ml}$ PW (Pepton Water), kemudian dihomogenkan dengan Vortex dan hasil homogenan ini adalah pengenceran $10^{-1}$. Disiapkan pengeceran $10^{-2}$, $10^{-3}$, dan $10^{-4}$ yang berisi $9 \mathrm{ml} \mathrm{PW}$. Diambil dengan pipet $1 \mathrm{ml}$ larutan homogenan dari tabung $10^{-1}$ lalu dipindahkan ke tabung PW $10^{-2}$ , $1 \mathrm{ml} \mathrm{PW} 10^{-2}$ dipindahkan ke tabung PW $10^{-3}$, dan $1 \mathrm{ml} \mathrm{PW} 10^{-3}$ dipindahkan ke tabung PW $10^{-4}$.

\section{Analisis Total Mikroba (Anon.,2017)}

Analisis total mikroba pada lawar putih dengan $3 \mathrm{M}^{\mathrm{TM}}$ Petrifilm ${ }^{T M}$ Aerobic Count Plates pada produk pangan. Diinokulasi $1 \mathrm{ml}$ dari tabung $10^{-2}$ sampai $10^{-4}$ ke tengah - tengah petriflim dan dilakukan secara duplo lalu diratakan permukaan petriflim AC dengan menggunakan spreader agar tidak terbentuk gelembung udara. Selanjutnya petriflim inkubasi pada suhu $35^{\circ} \mathrm{C}$ selama 24 jam di inkubator. Jumlah koloni mikroba yang terdapat dalam petriflim AC dihitung yang ditandai dengan koloni merah muda. Jumlah koloni menurut Fardiaz (1992) dihitung dengan rumus sebagai berikut :

Total mikroba $=$ jumlah koloni $x \frac{1}{\text { faktor pengenceran }}$

\section{Analisis Coliform dan E.coli (Anon., 2017)}

Analisis Coliform dan E.coli pada Lawar Putih daging babi menggunakan metode tuang dengan $3 \mathrm{M}^{\mathrm{TM}}$ Petrifilm ${ }^{T M}$ Escherichia coli and coliform count plates. Diinokulasi $1 \mathrm{ml}$ dari tabung $10^{-1}$ sampai tabung $10^{-3}$ ke tengah tengah petriflim EC yang dilakukan secara duplo. Diinkubasi petriflim EC pada suhu $35^{\circ} \mathrm{C}$ selama 24 jam di inkubator. Diamati perubahan yang terjadi, Coliform ditandai dengan koloni berwarna merah muda dan bergas. Setelah itu petriflim yang positif Coliform diinkubasi kembali selama 24 untuk uji penegasan penentuaan E.coli. Koloni yang positif E.coli ditandai dengan warna biru dan bergelembung gas pada petriflim.

\section{Analisis Staphylococcus Aureus (Anon., 2017)}

Analisis S.aureus menggunakan metode sebar dengan $3 \mathrm{M}^{\mathrm{TM}}$ Petrifilm ${ }^{T M}$ Staph Express System Count Plate pada produk olahan daging. Diinokulasi $1 \mathrm{ml}$ dari tabung $10^{-1}$ sampai tabung $10^{-3}$ ke tengah - tengah petriflim STX yang dilakukan secara duplo. Diinkubasi petriflim STX pada suhu $35^{\circ} \mathrm{C}$ selama 24 jam di inkubator. S.aureus memiliki ciri dengan koloni berwarna merah violet.

\section{HASIL DAN PEMBAHASAN}

\section{Total Mikroba}

Berdasarkan hasil pengujian menunjukkan bahwa total mikroba pada 11 lawar putih di rumah makan di kecamatan Denpasar Utara total mikroba tertinggi ditemukan pada $\mathrm{R}_{3}$ yaitu $7,6 \times 10^{6} \mathrm{koloni} / \mathrm{g}$ dan total mikroba terendah pada sampel $\mathrm{R}_{10}$ yaitu $6,7 \times 10^{5}$ koloni $/ \mathrm{g}$. Persyaratan batasan maksimum cemaran total mikroba pada produk olahan daging dengan perlakuan panas adalah $1 \times 10^{6} \mathrm{koloni} / \mathrm{g}$ sesuai dengan Peraturan Kepala BPOM Republik Indonesia Nomor 16 Tahun 2016 Tentang Kriteria Mikrobiologi Dalam Pangan Olahan (Anon., 2016). Hasil penelitian total mikroba pada lawar putih daging babi di rumah makan yang menjual lawar kecamatan Denpasar Utara dapat dilihat pada Tabel 1. 
Tabel 1. Total mikroba pada Lawar Putih daging Babi di rumah makan yang menjual lawar kecamatan Denpasar Utara

\begin{tabular}{|c|c|c|c|}
\hline $\begin{array}{l}\text { Sampel } \\
\text { Lawar }\end{array}$ & $\begin{array}{l}\text { Total Mikroba } \\
\text { Koloni/g }\end{array}$ & $\begin{array}{l}\text { BPOM } 2016 \text { olahan daging } \\
\text { koloni/g }\end{array}$ & Keterangan \\
\hline $\mathrm{R}_{1}$ & $1,5 \times 10^{6}$ & $1 \times 10^{6}$ & Tidak memenuhi syarat \\
\hline $\mathrm{R}_{2}$ & $3,0 \times 10^{6}$ & $1 \times 10^{6}$ & Tidak memenuhi syarat \\
\hline $\mathrm{R}_{3}$ & $7,6 \times 10^{6}$ & $1 \times 10^{6}$ & Tidak memenuhi syarat \\
\hline $\mathrm{R}_{4}$ & $3,3 \times 10^{6}$ & $1 \times 10^{6}$ & Tidak memenuhi syarat \\
\hline $\mathrm{R}_{5}$ & $7,0 \times 10^{5}$ & $1 \times 10^{6}$ & Memenuhi syarat \\
\hline $\mathrm{R}_{6}$ & $7,6 \times 10^{5}$ & $1 \times 10^{6}$ & Memenuhi syarat \\
\hline $\mathrm{R}_{7}$ & $9,5 \times 10^{5}$ & $1 \times 10^{6}$ & Memenuhi syarat \\
\hline $\mathrm{R}_{8}$ & $2,6 \times 10^{6}$ & $1 \times 10^{6}$ & Tidak memenuhi syarat \\
\hline $\mathrm{R}_{9}$ & $1,3 \times 10^{6}$ & $1 \times 10^{6}$ & Tidak memenuhi syarat \\
\hline $\mathrm{R}_{10}$ & $6,7 \times 10^{5}$ & $1 \times 10^{6}$ & Memenuhi syarat \\
\hline $\mathrm{R}_{11}$ & $1,0 \times 10^{6}$ & $1 \times 10^{6}$ & Memenuhi syarat \\
\hline
\end{tabular}

Hasil pengujian total mikroba pada Tabel 1 menunjukkan bahwa $45 \%$ lawar putih memiliki total mikroba dibawah $1 \times 10^{6}$ koloni/g. Hal ini menunjukkan bahwa lawar putih yang memenuhi syarat menghasilkan proses pengolahan, penyimpanan, dan praktek sanitasi yang baik sehingga berpengaruh terhadap keamanan pangan. Rempah-rempah yang digunakan dalam pembuatan lawar antara lain bawang merah, bawang putih, lengkuas, dan cabai juga berperan sebagai antimikroba pada olahan pangan (Jenie et al., 1992). Berdasarkan data dari hasil penelitian menunjukkan bahwa 55\% tidak memenuhi syarat. Tingginya jumlah total mikroba dapat disebabkan karena alat yang digunakan selama proses pengolahan tidak dicuci terlebih dahulu, dan daging yang telah dicincang disimpan disuhu ruang tanpa adanya perlakuan khusus akan mempengaruhi peningkatan pertumbuhan mikroba.

\section{Coliform dan Escherichis Coli}

Hasil pengujian Coliform dan E.coli pada lawar putih daging babi di rumah makan yang menjual lawar kecamatan Denpasar Utara.dapat dilihat pada Tabel 2.

Tabel 2. Uji Coliform dan E.coli pada pada lawar putih daging babi di rumah makan yang menjual lawar di kecamatan Denpasar Utara.

\begin{tabular}{ccccc}
\hline $\begin{array}{c}\text { Sampel } \\
\text { Lawar }\end{array}$ & $\begin{array}{c}\text { Coliform } \\
\text { Koloni/g) }\end{array}$ & E.coli (koloni/g) & $\begin{array}{c}\text { BPOM 2016 olahan } \\
\text { daging }(\text { koloni/g) }\end{array}$ & Keterangan \\
\hline $\mathrm{R}_{1}$ & $1,14 \times 10^{5}$ & $1,2 \times 10^{2}$ & 10 & Tidak memenuhi syarat \\
$\mathrm{R}_{2}$ & $2,59 \times 10^{5}$ & $6,6 \times 10^{2}$ & 10 & Tidak memenuhi syarat \\
$\mathrm{R}_{3}$ & $8,89 \times 10^{5}$ & $4,3 \times 10^{3}$ & 10 & Tidak memenuhi syarat \\
$\mathrm{R}_{4}$ & $4,98 \times 10^{5}$ & $4,0 \times 10^{2}$ & 10 & Tidak memenuhi syarat \\
$\mathrm{R}_{5}$ & $4,95 \times 10^{5}$ & $4,9 \times 10^{2}$ & 10 & Tidak memenuhi syarat \\
$\mathrm{R}_{6}$ & $1,16 \times 10^{5}$ & $1,5 \times 10^{3}$ & 10 & Tidak memenuhi syarat \\
$\mathrm{R}_{7}$ & $1,35 \times 10^{5}$ & $3,3 \times 10^{3}$ & 10 & Tidak memenuhi syarat \\
$\mathrm{R}_{8}$ & $5,4 \times 10^{4}$ & $6,4 \times 10^{2}$ & 10 & Tidak memenuhi syarat \\
$\mathrm{R}_{9}$ & $1,83 \times 10^{5}$ & $3,5 \times 10^{2}$ & 10 & Tidak memenuhi syarat \\
$\mathrm{R}_{10}$ & $3,9 \times 10^{4}$ & $5,0 \times 10^{2}$ & 10 & Tidak memenuhi syarat \\
$\mathrm{R}_{11}$ & $2,72 \times 10^{5}$ & $3,6 \times 10^{3}$ & 10 & Tidak memenuhi syarat \\
\hline
\end{tabular}


Hasil uji penegasan tersebut menunjukkan bahwa seluruh sampel lawar putih daging babi tidak memenuhi standar tentang batas cemaran mikroba pada olahan daging dengan perlakuan panas dengan batas cemaran E.coli yaitu 10 koloni/g sesuai dengan Peraturan Kepala BPOM Republik Indonesia Nomor 16 Tahun 2016 (Anon., 2016).

Keberadaan bakteri E.coli dalam daging menunjukkan bahwa bahan pangan tersebut pernah tercemar oleh kotoran manusia atau hewan, hal ini dapat mengkontaminasi peralatan dalam pengolahan, sehingga dalam mikrobiologi pangan E.coli disebut sebagai indikator sanitasi (Supardi dan Sukanto 1999). Sumber kontaminasi yang memungkinkan terjadinya cemaran berasal dari air yang telah terkontaminasi E.coli yang digunakan untuk mencuci daging, mencuci alat-alat, dan mencuci tangan selama bekerja tanpa menggunakan sabun. Dari hasil kuisioner juga diperoleh bahwa karyawan mencuci tangan seperlunya dan tidak menggunakan sabun, dan lemari kaca hanya dibersihkan bila terlihat kotor dengan kisaran waktu tiga kali seminggu menggunakan kain lap yang basah. Kontaminasi cemaran E.coli pada seluruh rumah makan yang menjual lawar putih daging babi akan berpengaruh terhadap keamanan pangan (Pohan, 2009).

\section{Staphylococcus aureus}

Hasil pengujian $S$. aureus pada lawar putih daging babi di rumah makan yang menjual lawar di kecamatan Denpasar Utara, dapat dilihat pada Tabel 3.

Tabel. 3 Uji Staphylococcus aureus pada lawar putih daging babo di rumah makan yang menjual lawar di kecamatan Denpasar Utara.

\begin{tabular}{cccc}
\hline $\begin{array}{c}\text { Sampel } \\
\text { Lawar }\end{array}$ & S. aureus $($ koloni/g) & $\begin{array}{c}\text { BPOM } 2016 \text { olahan daging } \\
\text { (koloni/g) }\end{array}$ & Keterangan \\
\hline $\mathrm{R}_{1}$ & $4,1 \times 10^{2}$ & $1 \times 10^{4}$ & Memenuhi syarat \\
$\mathrm{R}_{2}$ & $4,6 \times 10^{2}$ & $1 \times 10^{4}$ & Memenuhi syarat \\
$\mathrm{R}_{3}$ & $1,5 \times 10^{2}$ & $1 \times 10^{4}$ & Memenuhi syarat \\
$\mathrm{R}_{4}$ & $1,42 \times 10^{3}$ & $1 \times 10^{4}$ & Memenuhi syarat \\
$\mathrm{R}_{5}$ & $3,05 \times 10^{2}$ & $1 \times 10^{4}$ & Memenuhi syarat \\
$\mathrm{R}_{6}$ & $3,0 \times 10^{2}$ & $1 \times 10^{4}$ & Memenuhi syarat \\
$\mathrm{R}_{7}$ & $2,2 \times 10^{2}$ & $1 \times 10^{4}$ & Memenuhi syarat \\
$\mathrm{R}_{8}$ & $5,7 \times 10^{2}$ & $1 \times 10^{4}$ & Memenuhi syarat \\
$\mathrm{R}_{9}$ & $5,1 \times 10^{2}$ & $1 \times 10^{4}$ & Memenuhi syarat \\
$\mathrm{R}_{10}$ & $8,0 \times 10^{2}$ & $1 \times 10^{4}$ & Memenuhi syarat \\
$\mathrm{R}_{11}$ & $1,75 \times 10^{2}$ & $1 \times 10^{4}$ & Memenuhi syarat \\
\hline
\end{tabular}

Berdasarkan hasil dari penelitian yang telah dilakukan pada lawar putih daging babi di rumah makan yang menjual lawar di kecamatan Denpasar Utara, menunjukkan bahwa lawar putih daging babi terkontaminasi S.aureus dengan nilai terendah yaitu $1,5 \times 10^{2} \mathrm{koloni} / \mathrm{g}$, sedangkan tertinggi yaitu $1,42 \times 10^{3}$ sehingga lawar putih daging babi yang dijual di rumah makan yang menjual lawar di kecamatan Denpasar Utara memenuhi syarat batas cemaran mikroba pada produk olahan daging dengan perlakuan panas (Anon., 2016). Adapun batasan maksimum cemaran S.aureus dalam olahan daging dengan panas adalah $1 \times 10^{4}$ koloni/g. 


\section{Praktek sanitasi dan hygiene pada rumah makan yang menjual lawar}

\section{Kondisi bahan baku lawar}

Berdasarkan hasil survei penelitian menunjukkan bahwa sebanyak $100 \%$ produsen di rumah makan yang menjual lawar di kecamatan Denpasar Utara mendapatkan bahan baku dari pasar tradisional. Jenis babi yang digunakan untuk jadi lawar adalah babi lokal. Bahan baku yang dibeli oleh pengelola adalah daging babi yang baru disembelih di malam hari dan masih memiliki tampilan yang segar seperti warna merah cerah, tekstur tidak hancur, dan aroma yang khas daging babi. Kontaminasi bakteri patogen pada bahan baku dapat bermula dari pasar karena kondisi pasar yang tidak dijaga kebersihannya sehingga dapat mudah untuk bakteri untuk berkembang biak (Utari, 2016). Hasil survei terhadap kondisi dan penyimpanan bahan baku dalam pembuatan lawar babi dapat dilihat pada Tabel 4.

Tabel 4. Hasil survei terhadap tempat pembelian dan metode penyimpanan bahan baku pada lawar putih daging babi yang dijual pada rumah makan di kecamatan Denpasar Utara.

\begin{tabular}{|c|c|c|c|}
\hline No & Indikator/Variabel & Jumlah & Persentase \\
\hline 1 & Tempat pembelian bahan baku & & \\
\hline & - Pasar & 11 & $100 \%$ \\
\hline 2 & Jenis bahan baku ( babi ) & & \\
\hline & - Lokal & 11 & $100 \%$ \\
\hline 3 & $\begin{array}{l}\text { Bahan baku langsung diolah } \\
\text { - Ya } \\
\text { - Tidak }\end{array}$ & $\begin{array}{l}4 \\
7\end{array}$ & $\begin{array}{l}35 \% \\
65 \%\end{array}$ \\
\hline 4 & $\begin{array}{l}\text { Penyimpanan bahan baku } \\
\text { - Freezer } \\
\text { - Tidak disimpan }\end{array}$ & $\begin{array}{l}7 \\
4\end{array}$ & $\begin{array}{l}65 \% \\
35 \%\end{array}$ \\
\hline 5 & $\begin{array}{l}\text { Maksimal lama penyimpanan } \\
-<1 \text { hari } \\
- \text { tidak disimpan }\end{array}$ & $\begin{array}{l}4 \\
7\end{array}$ & $\begin{array}{l}65 \% \\
35 \%\end{array}$ \\
\hline
\end{tabular}

Berdasarkan hasil survei penelitian menunjukkan sebanyak 35\% daging babi yang diperoleh dari pasar langsung diolah oleh produsen untuk dijadikan lawar dan sebanyak $65 \%$ daging babi yang dibeli di pasar tidak langsung diolah namun disimpan di wadah tertutup kemudian dimasukkan ke dalam frezzer untuk diolah di pagi hari dengan kisaran waktu penyimpanan 8 jam.

\section{Kondisi proses pengolahan dan penyimpanan}

Berdasarkan hasil data survei penelitian bahwa produsen di rumah makan yang menjual lawar di kecamatan Denpasar Utara pada Tabel
5 menunjukkan bahwa sebanyak 35\% pembuatan adonan lawar di pagi hari pukul 06.00 sampai 09.00 wita. Namun sebanyak $65 \%$ produsen yang membuat adonan lawar di malam hari pada pukul 01.00 wita dan disajikan di pagi hari pukul 09.00 wita. Hal ini dapat memicu pertumbuhan mikroba karena lamanya waktu proses pengolahan, lokasi yang berbeda dan kontaminasi selama di dalam perjalanan. Sesuai dengan pengujian pada $\mathrm{R}_{1}, \mathrm{R}_{2}, \mathrm{R}_{3}, \mathrm{R}_{4}$, $\mathrm{R}_{8}, \mathrm{R}_{9}, \mathrm{R}_{11}$ maka terbukti total mikroba tidak memenuhi persyaratan karena telah melewati batas maksimum cemaran mikroba olahan daging. Hasil survei terhadap kondisi proses pembuatan bahan olahan lama penyimpanan 
dan wadah untuk membuat lawar putih daging

babi dapat dilihat pada Tabel 5 .

Tabel 5. Hasil survei kondisi terhadap proses pembuatan bahan olahan lama penyimpanan dan wadah untuk membuat lawar putih daging babi dan penyimpanan pada lawar putih daging babi di rumah makan yang menjual lawar di kecamatan Denpasar Utara

\begin{tabular}{|c|c|c|c|}
\hline No & Indikator/Variabel & Jumlah & Persentase \\
\hline \multirow[t]{3}{*}{1} & Waktu pembuatan bahan olahan Lawar & & \\
\hline & - Pagi & 4 & $35 \%$ \\
\hline & - Malam & 7 & $65 \%$ \\
\hline \multirow[t]{3}{*}{2} & Maksimal lama penyimpanan bahan yang telah di cincang dilemari kaca & & \\
\hline & $-4 \mathrm{jam}$ & 4 & $35 \%$ \\
\hline & $-5-12 \mathrm{jam}$ & 7 & $65 \%$ \\
\hline \multirow[t]{3}{*}{3} & Wadah yang digunakan mengolah lawar merah dan putih & & \\
\hline & - 1 baskom & 11 & $100 \%$ \\
\hline & - 2 baskom & 0 & $0 \%$ \\
\hline
\end{tabular}

Dalam proses penyimpanan bahan yang telah di cincang di lemari kaca, sebanyak 35\% rumah makan yang menjual lawar di kecamatan Denpasar Utara meyimpan bahan yang telah di cincang sampai 4 jam. Sebanyak $65 \%$ rumah makan yang menyajikan lawar lebih dari 4 jam. Bahan yang telah di cincang yang didiamkan lebih dari 4 jam dalam keadaan tidak tertutup akan meningkatkan pertumbuhan
E.coli seperti pada semua rumah makan yang menjual lawar.. Sebanyak $100 \%$ produsen membuat lawar merah dan lawar putih dalam 1 baskom.

\section{Praktek personal hygine}

Hasil survei terhadap personal higiene karyawan pada rumah makan yang menjual lawar di kecamatan Denpasar Utara dapat dilihat pada Tabel 6.

Tabel 6. Hasil survei terhadap personal higiene karyawan di rumah makan yang menjual lawar di kecamatan Denpasar Utara

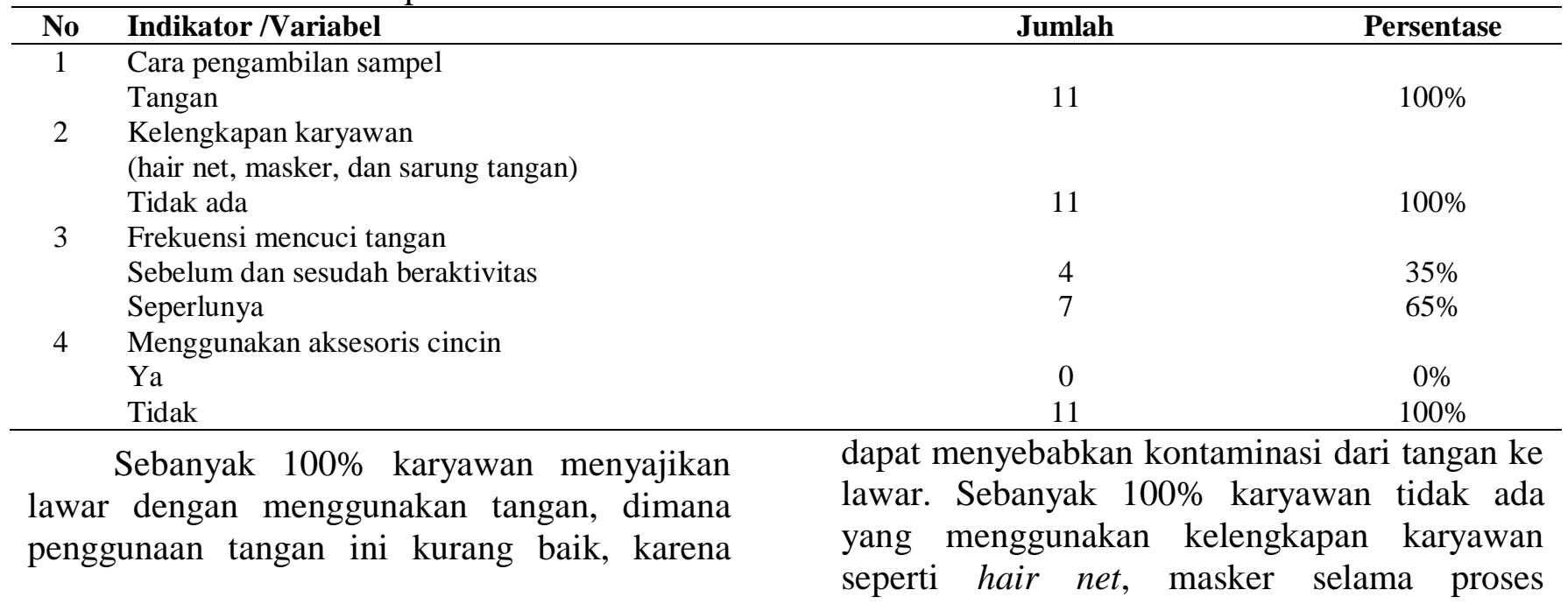


pengolahan dan sebanyak 35\% karyawan telah menerapkan prinsip mencuci tangan dengan sabun sesudah beraktivitas selama mengelola lawar namun sebanyak $65 \%$ hanya mencuci tangan jika diperlukan dan tidak menggunakan sabun.

Cemaran E.coli pada seluruh rumah makan yang menjual lawar di kecamatan Denpasar utara juga disebabkan karena karyawan yang mencuci tangan seperlunya dan tidak menggunakan sabun. Air yang tercemar E.coli dapat berpengaruh sehingga menyebabkan kontaminasi pada lawar. Hasil analisis mikroba pada lawar juga membuktikan bahwa semua rumah makan terkontaminasi E.coli. Frekuensi mencuci tangan yang dilakukan pekerja sebelum dan sesudah memulai aktivitas juga dapat menurunkan kontaminasi silang ke dalam produk. Kebiasaan mencuci tangan dapat membantu mencegah terjadinya penularan bakteri dari tangan ke makanan (Arisman, 2009). Sebanyak $100 \%$ karyawan tidak menggunakan aksesoris selama proses pengolahan lawar.

\section{Praktek sanitasi pada rumah makan yang menjual lawar}

Hasil survei terhadap praktek sanitasi di rumah makan yang menjual lawar di kecamatan Denpasar Utara dapat dilihat pada Tabel 7.

Tabel 7. Hasil survei terhadap praktek sanitasi di rumah makan yang menjual lawar di kecamatan Denpasar Utara

\begin{tabular}{|c|c|c|c|}
\hline No & Indikator/ Variabel & Jumlah & Persentase \\
\hline \multirow[t]{3}{*}{1} & Membersihkan lemari kaca & & \\
\hline & Ya & 0 & $0 \%$ \\
\hline & Tidak & 11 & $100 \%$ \\
\hline \multirow[t]{2}{*}{2} & Membersihkan peralatan pengolahan lawar & & \\
\hline & Ya & 11 & $100 \%$ \\
\hline \multirow[t]{2}{*}{3} & $\begin{array}{l}\text { Pembersihan dan sanitasi ruang pengolahan sebelum dan sesudah } \\
\text { aktivitas }\end{array}$ & & \\
\hline & Ya & 11 & $100 \%$ \\
\hline
\end{tabular}

Berdasarkan hasil survei dan pengamatan yang telah dilakukan, menunjukkan bahwa sebanyak $100 \%$ lemari kaca hanya dibersihkan jika terlihat kotor. Keberadaan E.coli dalam makanan juga dipengaruhi oleh kurangnya praktek sanitasi yang baik (Pratidina et al., 2017).

Proses membersihkan peralatan dalam proses pengolahan lawar di rumah makan yang menjual lawar secara keseluruhan menggunakan air mengalir yang dilakukan sebelum memulai aktivitas di rumah makan. Peralatan yang telah dibersihkan disimpan dalam keadaan yang kering.
Membersihkan lingkungan rumah makan juga dilakukan di pagi hari yang mencakup menyapu, mengepel, dan membuang limbah sampah.

\section{KESIMPULAN DAN SARAN}

\section{Kesimpulan}

Berdasarkan hasil penelitian yang telah dilakukan maka dapat disimpulkan beberapa hal sebagai berikut :

1. Sebanyak $45 \%$ lawar putih daging babi di rumah makan kecamatan Denpasar Utara sudah memenuhi syarat total mikroba 
pada produk olahan daging sedangkan $55 \%$ lawar putih daging babi tidak memenuhi syarat total mikroba. Lawar putih daging babi di rumah makan kecamatan Denpasar Utara tidak memenuhi syarat Escherichia coli pada produk olahan daging. Lawar putih daging babi di kecamatan Denpasar utara sudah memenuhi syarat Staphylococcus aureus pada produk olahan daging.

2. Rumah makan yang menjual lawar di kecamatan Denpasar Utara membeli bahan baku di pasar lokal, 65\% bahan baku langsung diolah dan 35\% bahan baku tidak langsung di gunakan, 35\% produsen mengolah lawar di pagi hari, $100 \%$ produsen mengolah lawar merah dan lawar putih pada 1 baskom, karyawan tidak menggunakan kelengkapan karyawan praktek sanitasi dan personal higiene kurang baik.

\section{Saran}

Berdasarkan hasil penelitian disarankan untuk:

1. Sebaiknya pengolahan lawar dilakukan di pagi hari di rumah makan yang menjual lawar di kecamatan Denpasar Utara dan tidak menyimpan bahan yang telah di cincang lebih dari 4 jam dalam keadaan tidak tertutup dan meningkatkan praktek sanitasi dan higiene di rumah makan yang menjual lawar di kecamatan Denpasar Utara dengan menggunakan kelengkapan karyawan pada saat pengolahan untuk menghindari kontaminasi mikroba patogen.

2. Sebaiknya memisahkan wadah pengolahan lawar merah dan lawar putih agar tidak terjadi kontaminasi silang.

\section{DAFTAR PUSTAKA}

Anonimus. 2008. SNI 2897:2008. Metode Pengujian Cemaran Mikroba Dalam Daging, Telur dan Susu, serta hasil olahannya. Badan Stardisasi Nasional, Jakarta.

Anonimus. 2016. Kriteria Mikrobiologi Dalam Pangan Olahan. Peraturan Kepala Badan Pengawas Obat Dan Makanan Republik Indonesia Nomor 16, Jakarta.

Anonimus. 2017. Interperatation Guide 3M Petriflim Microbiology. 3M Food Safety. 3M Petrfilim, Australia.

Arihantana, M. B. 1993. Tingkat Cemaran Coliform, Faecal Coliform dan Escherichia coli Pada Proses Penyediaan Lawar di Resturant/ Warung Makan di Sekitar Denpasar. Universitas Udayana, Denpasar

Arisman. 2009. Buku ajar ilmu gizi : Keracunan Makanan. Jakarta.

Candra P, S. Oktafia, M. Citra, M. Cahyani. 2013.Cemaran Eschericia Coli dan Coliform pada Lawar Merah yang Dijual di Daerah Pariwisata. Universitas Udayana, Denpasar

Fardiaz, S. 1992. Mikrobiologi Pengelolaan Pangan. Departemen Pendidikan dan Kebudayaan Direktorat Jendral Pendidikan Tinggi, Pusat Antar Universitas Pangan dan Gizi. Institut Pertanian Bogor, Bogor.

Jenie. B.S.L., K. Undriyani dan R. Dewanti. 2010. Pengaruh Konsentrasi Jahe dan Waktu Kontak terhadap aktivitas beberapa mikroba penyebab kerusakan pangan. Bul Ilmu dan Teknologi Pangan I1 1(2). 
Pohan S, D 2009. Pemeriksaan Escherichia coli pada usapan peralatan makan yang digunakan oleh pedagang makanan di pasar petisah medan tahun 2009. Skripsi FKM. USU, 2009.

Pratidina, P., Y.H. Darundiati dan H. L. Dangiran. 2017. Hubungan Higiene Dan Sanitasi Dengan Kontaminasi Escherichia coli Pada Jajanan Pedagang Kaki Lima di Sekolah Dasar Kelurahan Pendrikan Lor, Semarang. Jurnal Kesehatan Masyarakat. Vol 5. No. 5.

Soeparno. 2005. Ilmu dan Teknologi Daging, Cetakan III. Gadjah Mada University Press. Yogyakarta.

Sugiyono, 2007, Statistika Untuk Penelitian, Cetakan Keduabelas, Alfabeta, Bandung.

Supardi dan Sukanto. 1999. Mikrobiologi Dalam Pengolahan Dan Keamanan Produk Pangan. Alumni, Bandung.

Suter, I.K., I.M. Sugitha, I.W. Arga, I.G.P. Tengah, N.K. Putra, N. Werdi, N.M. Yusa, I.B.W.Gunam, K.A. Nocianitri, N.W. Wisaniyasa, I.P. Suparthana. 2010. Pangan Tradisional Bali : Kajian Aspek Sosial Budaya, Ekonomi, Pengolahan, Khasiat dan Keamanan. Pusat Kajian Makanan Tradisional Lembaga Penelitian Universitas Udayana, Denpasar.

Suter IK., 2009. Lawar. Program Studi Teknologi Pertanian. Universitas Udayana. Denpasar.

Trisdayanti, A.A.S. Sawitri, I.N. Sujaya. 2015. Hygiene sanitasi dan potensi keberadaan gen virulensi E. Coli pada lawar di
Kuta: Tantangan pariwisata dan kesehatan pangan di Bali. Public health and preventive medicine archive. Program Studi Kesehatan Masyarakat Fakultas Kedokteran Universitas Udayana, Denpasar

Utari, L.K. 2016. Status Mikrobiologi Daging Broiler di Pasar Tradisional Kabupaten Pringsewu, Skripsi. Fakultas Teknologi Pertanian. Univeristas Lampung, Lampung. 